\title{
Phylogenetic characterization of Canine Parvovirus VP2 partial sequences from symptomatic dogs samples
}

\author{
D. Zienius ${ }^{1}$, R. Lelešius ${ }^{1}$, H. Kavaliauskis ${ }^{2}$, A. Stankevičius ${ }^{3}$, A. Šalomskas ${ }^{2}$, \\ ${ }^{1}$ Institute of Microbiology and Virology, Veterinary Academy, Lithuanian University of Health Sciences, \\ Tilžès 18, 47181 Kaunas, Lithuania \\ ${ }^{2}$ Department of Infectious Diseases, Veterinary Academy, Lithuanian University of Health Sciences, \\ Kaunas, Lithuania \\ ${ }^{3}$ Department of Anatomy and Physiology, Veterinary Academy, Lithuanian University of Health Sciences, \\ Kaunas, Lithuania
}

\begin{abstract}
The aim of the present study was to detect canine parvovirus (CPV) from faecal samples of clinically ill domestic dogs by polymerase chain reaction (PCR) followed by VP2 gene partial sequencing and molecular characterization of circulating strains in Lithuania.

Eleven clinically and antigen-tested positive dog faecal samples, collected during the period of 2014-2015, were investigated by using PCR. The phylogenetic investigations indicated that the Lithuanian CPV VP2 partial sequences (3025-3706 cds) were closely related and showed 99.0-99.9\% identity. All Lithuanian sequences were associated with one phylogroup, but grouped in different clusters. Ten of investigated Lithuanian CPV VP2 sequences were closely associated with CPV 2a antigenic variant $(99.4 \% \mathrm{nt}$ identity). Five CPV VP2 sequences from Lithuania were related to CPV-2a, but were rather divergent (6.8 nt differences). Only one CPV VP2 sequence from Lithuania was associated (99.3\% nt identity) with CPV-2b VP2 sequences from France, Italy, USA and Korea. The four of eleven investigated Lithuanian dogs with CPV infection symptoms were vaccinated with CPV-2 vaccine, but their VP2 sequences were phylogenetically distantly associated with CPV vaccine strains VP2 sequences (11.5-15.8 nt differences).

Ten Lithuanian CPV VP2 sequences had monophyletic relations among the close geographically associated samples, but five of them were rather divergent (1.0\% less sequence similarity). The one Lithuanian CPV VP2 sequence was closely related with CPV-2b antigenic variant. All the Lithuanian CPV VP2 partial sequences were conservative and phylogenetically low associated with most commonly used CPV vaccine strains.
\end{abstract}

Key words: Canine parvovirus, dog, molecular epidemiology, Lithuania 


\section{Introduction}

Canine parvovirus (CPV) is the causative agent of acute haemorrhagic enteritis and myocarditis in dogs and it is one of the most important pathogenic viruses. CPV is a highly contagious virus and it causes often fatal diseases (Nandi and Kumar 2010). CPV, a member of the Parvoviridae family Protoparvovirus genus, contains a single strand DNA genome of about 5200 nucleotides that is packaged in an icosahedral capsid (Siegl et al. 1985, Cotmore et al. 2014). The genome is simple and contains two large open reading frames (ORF) as well some smaller or overlapping genes, mostly generated by alternative splicing. In the conventional orientation, the right-hand ORF encodes the capsid proteins and the left-hand one encodes the non-structural proteins (Hoelzer and Parrish 2010). CPV contains three capsid proteins: VP1, VP2 and VP3. VP2 is the highly antigenic major capsid protein, and it plays an important role in determining viral host range and tissue tropism (Hueffer et al. 2003). Amino acids substitutions in VP2 gene have been responsible for genetic and antigenic properties (Truyen 1999).

The virus emerged as dog pathogen in the late 1970 's as host variant of feline panleukopenia virus (FPLV) (Truyen 2006). A few years after its emergence, the original virus type CPV-2 was replaced by two new antigenic variants, CPV-2a and CPV-2b (Parrish et al. 1988). During the last ten years, a novel CPV mutant, CPV-2c, has widely distributed and co-exists with other CPV types in Europe (Decaro et al. 2011), North (Hong et al. 2007) and South (Perez et al. 2007) America countries. The identification of the subtypes of CPV-2 that are currently circulating in the canine population is essential for the understanding of viral evolution and the development of measures to control its spread (Pinto et al. 2012). All the three antigenic variants differ from the original type CPV-2 for a few amino acids in the VP2 protein, whereas genetic differences among the variants are determined only by residue 426 , with types $2 \mathrm{a}, 2 \mathrm{~b}$, and 2c displaying Asn, Asp, and Glu, respectively (Martella et al. 2006).

Polymerase chain reaction (PCR) is considered as the most reliable diagnostic technique having high degree of sensitivity and specificity in detecting CPV from faecal samples. PCR-based molecular typing of $\mathrm{CPV}$ also helps to gain new insights into pathogenesis of CPV-2 types (CPV-2a, CPV-2b and CPV-2c) and is extremely useful to understand antigenic differences between CPV types (Decaro et al. 2005a).

There is concern that the antigenic differences may decrease the effectiveness of the vaccine based on the original antigenic type CPV-2. Although the original vaccine has been shown to protect dogs against challenge from any of the current CPV types (Spibey et al. 2008), there are still many cases of clinical parvovirus infection in dogs. For example, in 2007, an outbreak of CPV-2c was reported in the dogs immunized with CPV-2-based vaccine in Italy (Decaro et al. 2008a).

In Lithuania, hemorrhagic enteritis in dogs caused by CPV-2 was first reported in 1995-1996 (Stankevicius and Salomskas 1998, Grigonis et al. 2002). The diagnostic criteria for CPV infection were based on clinical signs (enteritis, hemorrhagic gastroenteritis, gastroenteritis, vomiting and diarrhoea), the examination of blood and antibody titration: leukopenia (a white blood cell count - WBC of $<5000$ cells $/ \mu \mathrm{l}$ ) or a single CPV haemagglutination inhibition (HI) antibody titre $\geq 1: 5120$ (Glickman et al. 1985).

The aim of the present study was to detect CPV from faecal samples of clinically ill domestic dogs by polymerase chain reaction (PCR) followed by VP2 gene partial sequencing and molecular characterization of circulating strains in Lithuania. This is the first report of the CPV VP2 proteins partial nucleotide sequence analysis from clinical cases in Lithuania.

\section{Materials and Methods}

\section{Sample collection}

Faecal samples were collected from 25 dogs presented to different Veterinary Pet Clinics situated in Kaunas city (central part of Lithuania) during a period of 12 months from January 2014 to January 2015. At the animal hospital, the samples were emulsified $(10 \%, \mathrm{wt} / \mathrm{vol})$ in $1 \mathrm{ml}$ sterile phosphate-buffered saline (PBS, $\mathrm{pH} 7.2$ ) and stored at $-20^{\circ} \mathrm{C}$ for $1-2$ months prior to being sent for laboratory analysis. After thawing, the samples were centrifuged at $10,000 \mathrm{rpm}$ for 10 $\min$ at $4^{\circ} \mathrm{C}$. The cleared supernatants were frozen at $-80^{\circ} \mathrm{C}$ and collected for PCR amplification.

\section{DNA extraction}

DNA was extracted from samples of $10 \%$ faeces in PBS using the TRIzol method (Invitrogen, Life Technologies, MD, USA) following the manufacturer's recommendations. The supernatant containing the DNA was transferred to a new tube and stored at $-20^{\circ} \mathrm{C}$ until it was used in PCR. 
Table 1. Identification of Lithuanian CPV-positive dog faeces samples, used for PCR and sequence analysis.

\begin{tabular}{ccccccccc}
\hline $\begin{array}{c}\text { Sample } \\
\text { ID }\end{array}$ & Breed & $\begin{array}{c}\text { Age } \\
\text { (months) }\end{array}$ & Sex & $\begin{array}{c}\text { CPV } \\
\text { Vaccinated } \\
(+/-)\end{array}$ & $\begin{array}{c}\text { Sample } \\
\text { type }\end{array}$ & $\begin{array}{c}\text { CPV/CCV } \\
\text { Ag Test Kits } \\
(+/-)\end{array}$ & $\begin{array}{c}\text { Sample DNA } \\
\text { concentration } \\
\text { ng/ } \mu \text { l }\end{array}$ & $\begin{array}{c}\text { Amplified } \\
\text { PCR product } \\
\text { (bp) }\end{array}$ \\
\hline LTU2CPV2 & $\begin{array}{c}\text { West Highland } \\
\text { Terrier }\end{array}$ & 2.0 & Female & - & Faeces & + & 34.6 & 681 \\
\hline LTU4CPV2 & $\begin{array}{c}\text { German } \\
\text { Shepherd }\end{array}$ & 3.0 & Male & - & Faeces & + & 28.0 & 681 \\
\hline LTU5CPV2 & Mix & 3.0 & Male & - & Faeces & + & 19.7 & 681 \\
\hline LTU6CPV2 & Pekingese & 1.5 & Male & + & Faeces & + & 31.7 & 681 \\
\hline LTU7CPV2 & Pekingese & 2.5 & Female & + & Faeces & + & 19.8 & 681 \\
\hline LTU8CPV2 & Yorkshire & 2.0 & Female & - & Faeces & + & 10.6 & 681 \\
\hline LTU9CPV2 & Beagle & 1.5 & Female & - & Faeces & + & 5.9 & 681 \\
\hline LTU10CPV2 & Mix & 5.5 & Male & + & Faeces & + & 8.5 & 681 \\
\hline LTU12CPV2 & Spice dog & 2.5 & Female & - & Faeces & + & 6.9 & 681 \\
\hline LTU13CPV2 & Mix & 2.5 & Female & - & Faeces & + & 6.3 & 681 \\
\hline LTU31CPV2 & Chinese Crested & 3.0 & Female & + & Faeces & + & 8.9 & 681 \\
\hline
\end{tabular}

\section{Primers and PCR}

The PCR was developed using primer set specific for pCPV-2ab. The pCPV-2ab primer set amplifies part of VP2 gene of both CPV-2a and CPV-2b variants (3025 to 3706 nucleotide position of CPV genomic DNA) to yield a product size of $681 \mathrm{bp}$. The PCR was carried out in principle as described earlier (Kumar et al. 2011) with some modifications. Five $\mu 1$ of DNA sample was mixed with $34.5 \mu \mathrm{l}$ water, nuclease free (Thermo Scientific, Lithuania); 10xPCR buffer $\left(100 \mathrm{mM}\right.$ Tris- $\mathrm{HCl}\left(\mathrm{pH} 8.8\right.$ at $\left.25^{\circ} \mathrm{C}\right), 500 \mathrm{mM}$ $\mathrm{KCl}, 0.8 \%$ (v/v) Nonidet P40) $5 \mu \mathrm{l} ; 25 \mathrm{mM} \mathrm{MgCl}_{2} 3 \mu \mathrm{l}$ $(1,5 \mathrm{mmol} / \mathrm{l})$; dNTP's $(10 \mathrm{mM}) 1 \mu \mathrm{l}$; and Taq DNA polymerase (Thermo Scientific, Lithuania) $(5 \mathrm{U} / \mu \mathrm{l})$ 0,5,1 and primers pCPV-2ab (F) (5'-Gaa gag tgg ttg taa ata att -3 , position 3025-3045) and pCPV-2ab (R) (5'-Cct ata taa cca aag tta gtac-3', position 3685-3706) 10 pmol each. The thermocycling format: denaturation at $95^{\circ} \mathrm{C} / 5 \mathrm{~min} ; 35$ amplification cycles with denaturation at $95^{\circ} \mathrm{C} / 30 \mathrm{~s}$, annealing $55^{\circ} \mathrm{C} / 60 \mathrm{~s}$, extension at $72^{\circ} \mathrm{C} / 60 \mathrm{~s}$; and a final incubation at $72^{\circ} \mathrm{C} / 7$ min. A commercial CPV2a Virbagen Parvo-C vaccine (strain CPV 154, 107 TDCI50/1ml (tissue culture infective dose), Virbac Limited, UK) was used as a positive control and nuclease free water (Thermo scientific, Lithuania) - as a negative control.

\section{Agarose gel electrophoresis and PCR products purification}

A $25 \mu \mathrm{l}$ aliquot of amplified PCR product from each sample were separated on $1.5 \%$ agarose gel in TAE buffer ( $40 \mathrm{mM}$ Tris, $20 \mathrm{mM}$ acetic acid, $1 \mathrm{mM}$ EDTA), stained with ethidium bromide $(10 \mu \mathrm{l})$ and visualized under UV light. Consequently, PCR products were purified from agarose gel slice using Gene JET Gel Extraction Kit (Thermo Scientific, Lithuania) following the manufacturer's recommendations. The GeneJET ${ }^{\mathrm{TM}}$ purification column was discarded and the purified DNA was stored at $-20^{\circ} \mathrm{C}$.

\section{DNA sequencing and phylogenetic analysis}

Sequencing was performed using BigDye Terminator v3.1 Cycle Sequencing Kit (Applied Biosystems, Foster, CA, USA) according to manufacturer's protocol. The DNA was sequenced with the same primer set that was used in the preceding RT-PCR steps. The following reaction mixtures were used: terminator ready reaction mix $1.0 \mu \mathrm{l}$, template $10 \mathrm{ng}$, primer $3.2 \mathrm{pmol}$ and deionised water up to $10 \mu \mathrm{l}$. The following cycling condition was used: initial denaturation $96^{\circ} \mathrm{C} / 1 \mathrm{~min}$, followed for 25 cycles: $96^{\circ} \mathrm{C} / 10 \mathrm{~s}$, $50^{\circ} \mathrm{C} / 5 \mathrm{~s}$ and $60^{\circ} \mathrm{C} / 4 \mathrm{~min}$. Ethanol/EDTA precipita- 
Table 2. The CPV and FPLV reference strains used for Lithuania VP2 sequences phylogenetic analysis available from the GenBank database (http://www. ncbi.nlm.nih.gov).

\begin{tabular}{|c|c|c|c|}
\hline GenBank Nr. & Strain/isolate ID & $\begin{array}{l}\text { Antigenic variants, country } \\
\text { or vaccine producer }\end{array}$ & References \\
\hline FJ005252 & strain $96 / 02$ & CPV2a, Italy & Decaro et al. 2009 \\
\hline GU362934 & strain $12 / 08-B$ & CPV2a, Italy & Decaro et al. 2010 \\
\hline AF306447 & isolate 618 & CPV2a, Italy & Battilani et al. 2001 \\
\hline FJ005263 & strain $42 / 05-49$ & CPV2b, Italy & Decaro et al. 2009 \\
\hline FJ005195 & strain $136 / 00$ & CPV2c, Italy & Decaro et al. 2009 \\
\hline AY742935 & strain CPV-U6 & CPV2a, Germany & Shackelton et al. 2005 \\
\hline AY742953 & strain CPV-435 & CPV2a, Germany & Shackelton et al. 2005 \\
\hline FJ005260 & strain G82/97 & CPV2b, Germany & Decaro et al. 2009 \\
\hline FJ005198 & strain G133/97 & CPV2c, Germany & Decaro et al. 2009 \\
\hline DQ025986 & isolate $04 \mathrm{~S} 17$ & CPV2a, France & Unpublished (direct submission) \\
\hline DQ025992 & isolate $04 \mathrm{~S} 23$ & CPV2b, France & Unpublished (direct submission) \\
\hline KF500497 & isolate $\mathrm{TR} / \mathrm{CPV} / \mathrm{K} 12-\mathrm{A}$ & CPV2a, Turkey & Unpublished (direct submission) \\
\hline KF500499 & isolate TR/CPV/K20-KM & CPV2b, Turkey & Unpublished (direct submission) \\
\hline JF280912 & strain TR-SS & FPLV, Turkey & Muz et al. 2012 \\
\hline GQ865519 & strain GR09/09 & CPV2c, Greece & Ntafis et al. 2010 \\
\hline GQ865518 & strain GR51/08 & CPV2c, Greece & Ntafis et al. 2010 \\
\hline FJ005247 & strain $195 / 08$ & CPV2c, Belgium & Decaro et al. 2009 \\
\hline FJ005214 & strain $67 / 06$ & CPV2c, Spain & Decaro et al. 2009 \\
\hline Z46651 & strain 46 & CPV2b, Poland & Unpublished (direct submission) \\
\hline EU145958 & isolate $\mathrm{CPV} / \mathrm{BJ} 069 / \mathrm{O} 7$ & CPV2a, China & Unpublished (direct submission) \\
\hline KC556950 & isolate $\mathrm{CPV} / \mathrm{Jiangsu} / 59$ & CPV2a, China & Unpublished (direct submission) \\
\hline KC556956 & isolate $\mathrm{CPV} / \mathrm{Jiangsu} / 60$ & CPV2b, China & Unpublished (direct submission) \\
\hline EF599097 & isolate DH326 & CPV2b, South Korea & Kang et al. 2008 \\
\hline EU009206 & strain K031 & CPV2b, South Korea & Jeoung et al. 2008 \\
\hline AJ698134 & isolate Indian & CPV2a, India & Unpublished (direct submission) \\
\hline DQ182623 & isolate IIL P20 & CPV2b, India & Chinchkar et al. 2006 \\
\hline AB054220 & strain V217 & CPV2b, Japan & Ikeda et al. 2000 \\
\hline AB054225 & strain V142 & FPLV, Japan & Ikeda et al. 2000 \\
\hline M38245 & strain CPV-b & CPV2b, USA & Parrish 1991 \\
\hline M24003 & isolate $\mathrm{CPV}-15$ & CPV2a, USA & Parrish et al. 1988 \\
\hline M74849 & isolate 39 & CPV2b, USA & Unpublished (direct submission) \\
\hline AY742955 & strain CPV-436 & CPV2b, USA & Shackelton et al. 2005 \\
\hline FJ005235 & strain $67 / 07-11$ & CPV2c, USA & Decaro et al. 2009 \\
\hline M38246 & isolate CU-4 & FPLV, USA & Parrish 1991 \\
\hline JF796200 & strain PassoFundo/6 & CPV2a, Brazil & Pinto et al. 2012 \\
\hline JF796195 & strain Parana/9 & CPV2c, Brazil & Pinto et al. 2012 \\
\hline EU018144 & isolate ARG02 & FPLV, Argentina & Unpublished (direct submission) \\
\hline AJ007500 & isolate CPV-Africa 9 & CPV2a, Africa & Unpublished (direct submission) \\
\hline AJ007498 & isolate CPV-Africa 3 & CPV2b, Africa & Unpublished (direct submission) \\
\hline AY742933 & strain CPV-339 & CPV2a, New Zeland & Shackelton et al. 2005 \\
\hline FJ011098 & strain Intervet/vaccine/06 & CPV2a, Intervet & Unpublished (direct submission) \\
\hline FJ011097 & strain Merial/vaccine/06 & CPV2a, Merial & Unpublished (direct submission) \\
\hline FJ197847 & strain CPVpf (vaccine) & CPV2a, S. Korea, Pfizer & Yoon et al. 2009 \\
\hline GU212792 & strain VAC_S quantum & $\begin{array}{l}\text { CPV2b, Thailand, } \\
\text { Schering Quantum }\end{array}$ & Phromnoi et al. 2010 \\
\hline EU498681 & strain Felocell (vaccine) & FPLV, Felocell & Decaro et al. $2008 b$ \\
\hline EU498680 & strain Purevax (valcine) & FPLV, Purevax & Decaro et al. $2008 b$ \\
\hline
\end{tabular}


tion method used for the extension products purification. ABI Prism 310 Genetic Analyzer used for samples electrophoresis and data analysis. The sequencing results were prepared in the $\mathrm{ABI}$ format (chromatogram) and analyzed by Chromas (version 2.01, Technelysium, Australia), saved in the FASTA format and used for the next investigation.

Evolutionary analysis was conducted in MEGA6 (Tamura et al. 2013). Multiple alignments were carried out using ClustalX program (Thompson et al. 1997). The evolutionary history was inferred by using the Maximum Likelihood method based on the Tamura-Nei model (Tamura and Nei 1993). Initial tree for the heuristic search was obtained by applying the Neighbor-Joining method (Saitou and Nei 1987) to a matrix of pairwise distances estimated using the Maximum Composite Likelihood (MCL) approach (Felsenstein 1981). The tree was drawn to scale, with branch lengths measured in the number of substitutions per site. The analysis involved 58 nucleotide sequences. There were a total of 3651 positions in the final dataset, the percentage of replicate trees in which the associated taxa were clustered together in the bootstrap test shown next to the branches.

After analysis, the obtained sequences from Lithuania (Table 1) were compared with those of other reference CPV and FPLV strains (Table 2) available from the GenBank database (http://www. ncbi.nlm.nih.gov).

\section{Results}

All the 25 dogs, included in the CPV sample collection and investigation, showed the characteristic CPV infection symptoms of fever, diarrhoea or hemorrhagic diarrhoea and vomiting. All faeces samples of the suspected dogs were positive tested by practitioners using a rapid test for simultaneous detection of $\mathrm{CPV}$ and Canine coronavirus (CCoV) antigens (Anigen, Rapid CPV/CCV Ag Test Kits - chromatographic immunoassay for the qualitative detection of $\mathrm{CPV}$ and $\mathrm{CCoV}$ antigens in canine faeces, Bio Note, Korea).

The PCR investigations with the pCPV-2ab (F) and $\mathrm{pCPV}-2 \mathrm{ab}(\mathrm{R})$ primer set revealed positive results in all tested faeces samples. After DNA purification, the best 15 PCR positive CPV products (DNA concentration $>5.0 \mathrm{ng} / \mu \mathrm{l}$ ) were selected and identified as acceptable for sequencing step. Sequencing (forward and reverse) with the amplification primers yielded 681 bases of sequence on average, which each then trimmed to a consensus $675 \mathrm{nt}$ for comparative analysis. The most specific eleven Lithuanian CPV2 sequences were selected for phylogenetic analysis
(Table 1). The sequence evolutionary relationships of the different Lithuanian CPV samples ( $\mathrm{n}=11), \mathrm{CPV} 2$ field $(n=37)$ and vaccine $(n=4)$ viruses as well as FPLV VP2 sequences $(n=6)$ from various parts of Europe, Asia and America were identified (Fig. 1). All positions containing gaps and missing data were eliminated from the dataset (complete deletion option). The sequences in Maximum Likelihood tree were subdivided into two main phylogenetic groups (I and II, bootstrap support of $62 \%$ ) and eight main clusters in phylogroup I (bootstrap support of 48-55\%). The FPLV field isolates from Turkey (JF280912FPLV), Japan (AB054225FPLV), Argentina (EU018144FPLV) and USA (M38246FPLV) were phylogenetically closely associated $(99.4 \% \mathrm{nt}$ identity) as the same as vaccine strains $(99.6 \% \mathrm{nt}$ identity) EU498681FPLV (Felocell) EU498680FPLV (Purevax) VP2 sequences clustered separately (Fig. 1, phylogenetic group II) as outgoing group. This group was distantly associated with all of phylogroup (I) CPV VP2 sequences (96.4\% nt identity), including all the CPV VP2 sequences from Lithuania $(96.7 \% \mathrm{nt}$ identity).

Sequence comparisons showed nucleotide identities of $99.0-99.9 \%$ among the CPV strains VP2 sequences in Lithuanian samples. All the Lithuanian sequences were associated in phylogroup I (Fig. 1), but grouped in different clusters. The phylogenetic tree shows that the five Lithuanian CPV VP2 sequences isolated in this study predominantly clustered in a distinct clade (cluster 1) and were closely associated $(99.6 \% \mathrm{nt}$ identity), but the one sequence (LTU9CPV2) was rather divergent $(99.0 \%$ nt identity). The all five Lithuanian CPV sequences from first cluster were associated (99.3\% nt identity) with the CPV sequence from Italy (GU362934CPV2a). The cluster 2 was connected with the first cluster and contained two CPV sequences from Lithuania (LTU2CPV2 and LTU4CPV2) and the sequence FJ005252CPV2a from Italy ( $99.5 \%$ nt identity). The CPV sequence LTU7CPV2 was grouped together (99.3\% nt identity, cluster 3) with CPV sequences from France (DQ025986CPV2a), Germany (AY742935CPV2a) and Italy (AF306447CPV2a). Two CPV2 sequences (cluster 4) from Lithuania (LTU6CPV2 and LTU13CPV2) were closely related (99.6\% nt identity) to the CPV isolates VP2 sequences from Turkey (KF500499CPV2b; KF500497CPV2a).

In one Lithuanian dog CPV2 isolate VP2-sequence (cluster 6) was rather divergent: the sequence LTU31CPV2 isolate was associated $(99.3 \%$ nt identity) with CPV isolates VP2 sequences from France (DQ025992CPV2b) and Italy (FJ005263CPV2b). Clusters 5 and 7 included more than two types of 


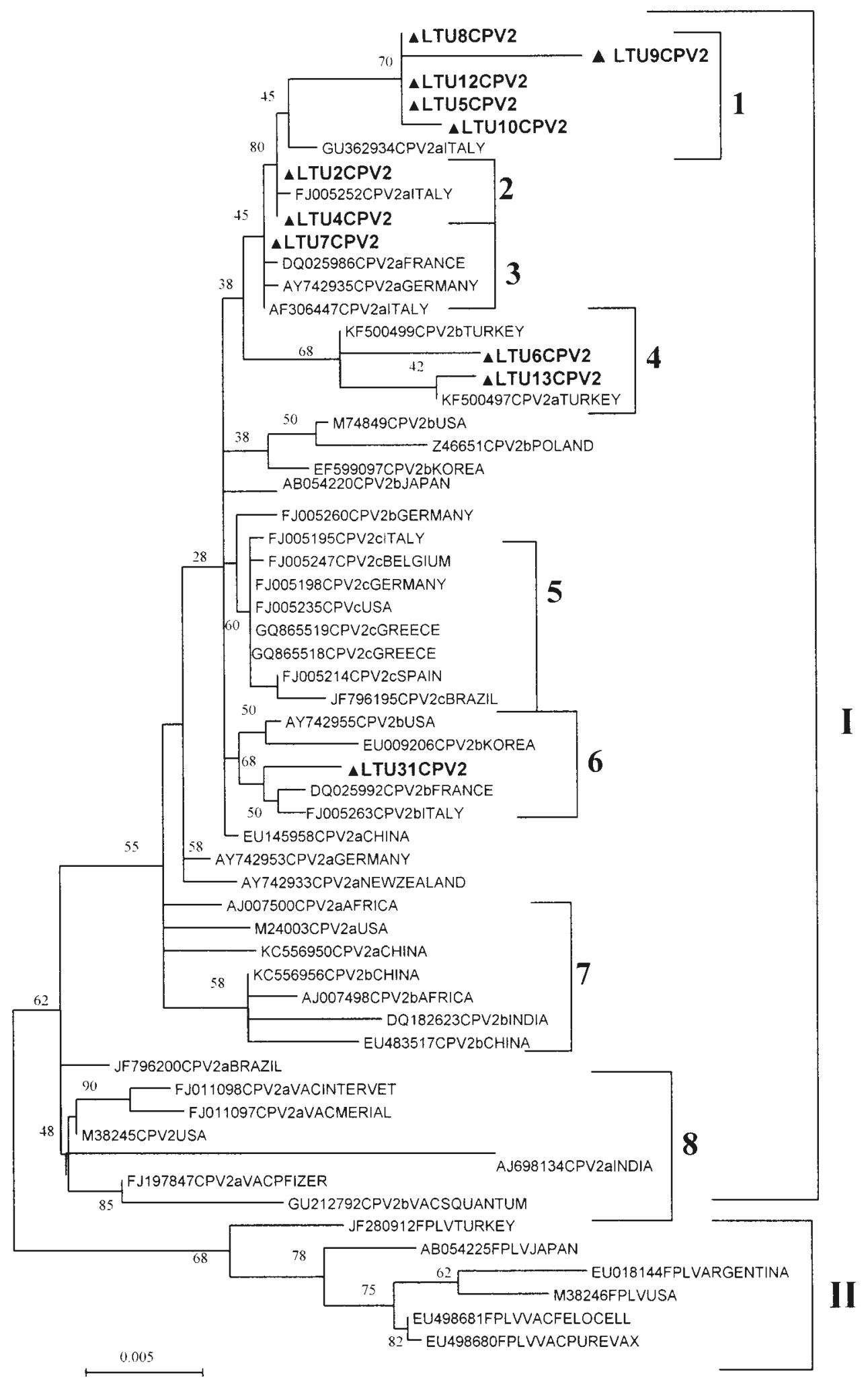

Fig. 1. The Maximum Likelihood phylogenetic tree of CPV VP2-coding (675 bp) region showing the relationships among 58 isolates of CPV. The tree with the highest log likelihood (-7330.6468) is shown. Lithuanian CPV isolates (n=11) VP2-sequences are presented in $\mathbf{\Delta}$ Bold. Evolutionary analysis was conducted in MEGA6 (Tamura et al. 2013). 
$\mathrm{CPV}$, indicating weak variation within the two clusters ( $2 \mathrm{a}, 2 \mathrm{~b}$ and $2 \mathrm{c}$ ). However, the cluster 5 was monophyletic and joined all the CPV $2 \mathrm{c}$ new antigenic variants from Germany, Italy, Belgium, USA, Greece, Spain and Brazil (99.5\% nt identity). The cluster 7 was more divergent and associated with CPV $2 \mathrm{a}$ and sequences from Africa, USA, China (98.8\% nt identity), and CPV $2 b$ from Africa, China and India (99.0\% nt identity). Thus the majority of CPV sequences were clustered separately depending on their type. So the cluster 8 was based on CPV 2a antigenic variant and contained strongly connected $(99.6 \% \mathrm{nt}$ identity) CPV vaccine strains VP2 sequences FJ011098CPV2a (Intervet), FJ011097CPV2a (Merial) FJ197847CPV2a (Pfizer) GU212792CPV2b (Schering Quantum) and weak associated (98.3\% nt identity) CPV isolates from USA (M38245CPV2) and India (AJ698134CPV2a).

The statistical comparative evaluation of nucleotides and amino acids (nt/aa) differences per sequence of all the identified CPV strains VP2 sequences in Lithuanian samples showed, that average of nt/aa differences within the Lithuanian isolates were 4.58/1.75 respectively. The identical investigation between Lithuanian and the others CPV isolates VP2 sequences included in statistical analysis indicated the 7.25/2.45 nt/aa differences. Although, ten of investigated Lithuanian CPV VP2 sequences were closely associated with CPV 2a antigenic variant $(99.4 \% \mathrm{nt}$ identity), but one sample (LTU31CPV2) - with CPV $2 \mathrm{~b}$ antigenic variant ( $99.3 \% \mathrm{nt}$ identity).

\section{Discussion}

The analysis of canine parvovirus retrospective epidemiology showed, that CPV can be one of the most important agents of gastrointestinal diseases in Lithuania. As in the other countries (Filipov et al. 2011), in Lithuania, diagnosis of parvovirosis in dogs was based only on clinical signs and rapid (enzyme-linked or chromatographic immunosorbent assay based) tests, which are often used in small animal practices without interpretation of possible false-negative results and without comparison with other methods. In contrast (Desario et al. 2005) with and similar (Filipov et al. 2011) to previous reports there was a good correlation between the antigen-detection test and PCR methods, all of PCR investigated Lithuanian dog faeces samples being recognized as positive. Most of the CPV PCR positive faeces samples (18 of 25 tested), were from dogs with signs of haemorrhagic gastroenteritis. The main source of the infection seems to be the faeces of infected dogs as more as $10^{9}$ virus particles/g can be shed during acute phase of the enteric form and virus survives at least 4 months in the faeces in the environment. So PCR is considered as the most reliable diagnostic technique having high degree of sensitivity and specificity in detecting CPV from faecal samples (Decaro et al. 2005b).

PCR based sequence analysis has revolutionized our knowledge of the spatial and temporal dynamics of CPV infection and also helps to gain new insights into pathogenesis and antigenic differences between CPV-2 types (Clegg et al. 2011). Phylogenetic analysis of the CPV2 variants circulating in the canine population of central Lithuania has shown that they are similar, but not identical to those found in other countries (including Europe). Except for a few nodes, the resulting Maximum Likelihood tree (Fig. 1) was not supported by high bootstrap values, showing that the partial sequences of the VP2 gene is not highly informative from phylogenetic point of view due to the low variability observed (2-42 nt). Phylogenetically the analysed canine parvoviruses fall into two distinct clades with the longest internal branch separating the FPLV-like viruses (Fig. 1, phylogroup II) from the viruses isolated from dogs (Fig. 1, phylogrpoup I). Phylogenetic analysis revealed that all CPV variants were descended from a single ancestor emerged during the mid-1970s and was closely related to the longknown FPLV which infects cats, minks, and raccoons but not dogs or cultured dog cells (Truyen 2006). There were more than $98 \%$ sequence homology and as few as six coding nucleotide differences in the VP2 gene at positions 3025, 3065, 3094, 3753, 4477 and 4498 (Truyen et al. 1995). Comparison of the entire genomes of the viruses showed that FPLV sequences were distinguished from CPV sequences by a total of 16 substitutions, of which 11 were located in the capsid protein genes, emphasizing the important role of the capsid in this emergence event (Hoelzer et al. 2008).

All currently known CPV-2- and CPV-2a-derived viruses are monophyletic, indicating that a single cross-species transmission event gave rise to all currently known CPV strains (Shackelton et al. 2005, Hoelzer et al. 2008). The same monophyletic clustering was observed in the Maximum Likelihood tree (Fig. 1) where the CPV sequences from Lithuania were closely related (more than $99 \%$ nt identity) to CPV-2a VP2 sequences from Italy (cluster 2), France, Germany (cluster 3) or Turkey (cluster 4). However, five CPV VP2 sequences from Lithuania (cluster 1) were related to CPV-2a, but were rather divergent (6.8 nt differences) from others tree clusters. Only one CPV VP2 sequence from Lithuania (LTU31CPV2) was associated with CPV-2b VP2 sequences from France, Italy, USA and Korea (cluster 
6). As it was expected and reported previously (Decaro et al. 2009) all the CPV-2c VP2 sequences formed a monophyletic cluster (cluster 7). Despite the strong phylogenetic association with CPV-2a ancestor, the Lithuanian CPV VP2 sequences show more or less geographically defined evolution pattern (especially five CPV samples in the first cluster), as were identified in other regions and studies (Battilani et al. 2002, Wang et al. 2005, Kang et al. 2008). Phylogenetic analysis showed some evidence for geographical clustering at an international level, suggesting that currently there are limited opportunities for global transmission, as has previously been suggested by others (Hoelzer et al. 2008). Despite this observation, sequences from individual countries, as exemplified by the United Kingdom, were generally not monophyletic, implying that national diversity is produced by a combination of local evolution occasionally supplemented by importation of new sequence types. This geographical restriction of certain virus types highlights the importance of rigorous, epidemiologically representative sampling strategies for the study of viral molecular epidemiology (Clegg et al. 2011).

Whether the CPV epidemiology in other Eastern European countries (Filipov et al. 2011) is related to different canine vaccination protocols or trade practices should be evaluated carefully in the future. The four of eleven investigated Lithuanian dogs (Table 1) with CPV infection symptoms were vaccinated with CPV-2 vaccine (one time), but their VP2 sequences were phylogenetically distantly associated with CPV vaccine strains VP2 sequences (11.5-15.8 nt differences). All the CPV-2a vaccine VP2 sequences were strongly determined and closely related (bootstrap support 90 and 85 ) in cluster 8 (Fig. 1). As previously found (Decaro et al. 2007), the occurrence of $\mathrm{CPV}$-induced gastroenteritis in regularly vaccinated dogs poses intriguing questions about the real efficacy of currently available (type 2 based) vaccines against the infection and diseases caused by the antigenic variants. In this case, this was indeed the main reason that the virus was sent for further identification following the initial confirmation of the presence of CPV in the faeces using an in-clinic test kit. Quick test kits can detect the presence of parvovirus, but will not be able to distinguish the type involved. In order to confirm whether the isolate is a field strain or a vaccine one it is often sufficient to type the virus since the original 'type 2' virus is no longer present in the field (Parrish et al. 1985). In such cases, the identification of type $2 \mathrm{a}, 2 \mathrm{~b}$ or $2 \mathrm{c}$ would be sufficient to confirm a field infection. The manufacturers were initially able to use specific PCR probes to differentiate between the unique genetic fingerprint of the vaccine strain and all other CPV strains, thus confirming that the isolate was not a vaccine one (Sutton et al. 2013). Moreover, nowadays there is a particular interest in the CPV once the virus has involved to a new viral variant that has been detected in several parts of the world. This becomes significant as most of the currently available vaccines are manufactured with CPV-2, and the crossimmunity between these different genotypes is not totally understood. Some authors have suggested an update of the virus strains in current vaccines, taking into account the existing partial protection (Truyen 2006). Because of this, the isolation of new CPV circulating variants is important in order to be used in vaccine manufactures more effective from an immunogenic point of view (Puentes et al. 2012).

\section{Conclusion}

Phylogenetic investigations of the Lithuanian CPV VP2 partial sequences identified monophyletic relations among the close geographically associated CPV samples. Ten of the eleven VP2 sequences from Lithuania were related to CPV-2a antigenic variant, but 5 of them were rather divergent and demonstrated $1.0 \%$ less sequence similarity to CPV-2a isolates from France, Germany or Turkey. The one Lithuanian CPV VP2 sequence was closely related with CPV-2b antigenic variants from France, Italy, USA and Korea. All of the Lithuanian CPV VP2 partial sequences were conservative and phylogenetically low associated with most commonly used CPV vaccine strains.

\section{References}

Battilani M, Ciulli S, Tisato E, Prosperi S (2002) Genetic analysis of canine parvovirus isolates (CPV-2) from dogs in Italy. Virus Res 83: 149-157.

Battilani M, Scagliarini A, Tisato E, Turilli C, Jacoboni I, Casadio R, Prosperi S (2001) Analysis of canine parvovirus sequences from wolves and dogs isolated in Italy. J Gen Virol 82: 1555-1560.

Chinchkar SR, Mohana Subramanian B, Hanumantha Rao N, Rangarajan PN, Thiagarajan D, Srinivasan VA (2006) Analysis of VP2 gene sequences of canine parvovirus isolates in India. Arch Virol 151: 1881-1887.

Clegg SR, Coyne KP, Parker J, Dawson S, Godsall SA, Pinchbeck G, Cripps PJ, Gaskell RM, Radford AD (2011) Molecular Epidemiology and Phylogeny Reveal Complex Spatial Dynamics in Areas Where Canine Parvovirus Is Endemic. J Virol 85: 7892-7899.

Cotmore SF, Agbandje-McKenna M, Chiorini JA, Mukha DV, Pintel DJ, Qiu J, Soderlund-Venermo M, Tattersall P, Tijssen P, Gatherer D, Davison AJ (2014) The family Parvoviridae. Arch Virol 159: 1239-1247.

Decaro N, Desario C, Billi M, Mari V, Elia G, Cavalli A, 
Martella V, Buonavoglia C (2011) Western European epidemiological survey for parvovirus and coronavirus infections in dogs. Vet J 187: 195-199.

Decaro N, Desario C, Elia G, Campolo M, Lorusso A, Mari V, Martella V, Buonavoglia C (2007) Occurrence of severe gastroenteritis in pups after canine parvovirus vaccine administration: a clinical and laboratory diagnostic dilemma. Vaccine 25: 1161-1166.

Decaro N, Desario C, Elia G, Martella V, Mari V, Lavazza A, Nardi M, Buonavoglia C (2008a) Evidence for immunisation failure in vaccinated adult dogs infected with canine parvovirus type 2c. New Microbiol 31: 125-130.

Decaro N, Desario C, Miccolupo A, Campolo M, Parisi A, Martella V, Amorisco F, Lucente MS, Lavazza A, Buonavoglia C (2008b) Genetic analysis of feline panleukopenia viruses from cats with gastroenteritis. J Gen Virol 89: 2290-2298.

Decaro N, Desario C, Parisi A, Martella V, Lorusso A, Miccolupo A, Mari V, Colaianni ML, Cavalli A, Di Trani L, Buonavoglia C (2009) Genetic analysis of canine parvovirus type 2c. Virology 385: 5-10.

Decaro N, Buonavoglia D, Desario C, Amorisco F, Colaianni ML, Parisi A, Terio V, Elia G, Lucente MS, Cavalli A, Martella V, Buonavoglia C (2010) Characterisation of canine parvovirus strains isolated from cats with feline panleukopenia. Res Vet Sci 89: 275-278.

Decaro N, Elia G, Campolo M, Desario C, Lucente MS, Bellacicco AL, Buonavoglia C (2005a) New approaches for the molecular characterization of canine parvovirus type 2 strains. J Vet Med 52: 316-319.

Decaro N, Elia G, Martella V, Desario C, Campolo M, Trani L, Tarsitano E, Tempesta M, Buonavoglia C (2005b) A real-time PCR assay for rapid detection and quantitation of canine parvovirus type 2 in the feces of dogs. Vet Microbiol 105: 19-28.

Desario C, Decaro N, Campolo M, Cavalli A, Cirone F, Elia G, Martella V, Lorusso E, Camero M, Buonavoglia C (2005) Canine parvovirus infection: which diagnostic test for virus? J Virol Methods 126: 179-185.

Felsenstein J (1981) Evolutionary trees from DNA sequences: a maximum likelihood approach. $\mathrm{J}$ Mol Evol 17: 368-376.

Filipov C, Decaro N, Desario C, Amorisco F, Sciarretta R, Buonavoglia $C$ (2011) Canine parvovirus epidemiology in Bulgaria. J Vet Diagn Invest 23: 152-154.

Glickman LT, Domanski LM, Patronek GJ, Visintainer F (1985) Breed-related risk factors for canine parvovirus enteritis. J Am Vet Med Assoc 187: 589-594.

Grigonis A, Macijauskas V, Zamokas G (2002) Examination of liver functions in dogs with parvovirus enteritis. Vet zootech-lith 17: 72-77.

Hoelzer K, Parrish CR (2010) The emergence of parvoviruses of carnivores. Vet Res 41: 39.

Hoelzer K, Shackelton LA, Parrish CR, Holmes EC (2008) Phylogenetic analysis reveals the emergence, evolution and dispersal of carnivore parvoviruses. J Gen Virol 89: 2280-2289.

Hong C, Decaro N, Desario C, Tanner P, Pardo MC, Sanchez S, Buonavoglia C, Saliki JT (2007) Occurrence of canine parvovirus type $2 \mathrm{c}$ in the United States. J Vet Diagn Invest 19: 535-539.

Hueffer K, Parker JS, Weichert WS, Geisel RE, Sgro JY, Parrish CR (2003) The natural host range shift and sub- sequent evolution of canine parvovirus resulted from virus-specific binding to the canine transferrin receptor. J Virol 77: 1718-1726.

Ikeda Y, Mochizuki M, Naito R, Nakamura K, Miyazawa T, Mikami T, Takahashi E (2000) Predominance of canine parvovirus $(\mathrm{CPV})$ in unvaccinated cat populations and emergence of new antigenic types of CPVs in cats. Virology 278: 13-19.

Jeoung SY, Ahn SJ, Kim D (2008) Genetic analysis of VP2 gene of canine parvovirus isolates in Korea. J Vet Med Sci 70: 719-722.

Kang BK, Song DS, Lee CS, Jung KI, Park SJ, Kim EM, Park BK (2008) Prevalence and genetic characterization of canine parvoviruses in Korea. Virus Genes 36: 127-133.

Kumar M, Chidri S, Nandi S (2011) A sensitive method to detect canine parvoviral DNA in faecal samples by nested polymerase chain reaction. Indian $\mathrm{J}$ Biotechnology 10: $183-187$.

Martella V, Decaro N, Buonavoglia C (2006) Evolution of CPV-2 and implication for antigenic/genetic characterization. Virus Genes 33: 11-13.

Muz D, Oguzoglu TC, Timurkan MO, Akin H (2012) Characterization of the partial VP2 gene region of canine parvoviruses in domestic cats from Turkey. Virus Genes 44(2):301-308.

Nandi S, Kumar M (2010) Canine parvovirus: current perspective. Indian J Virol 21: 31-44.

Ntafis V, Xylouri E, Kalli I, Desario C, Mari V, Decaro N, Buonavoglia C (2010) Characterization of Canine parvovirus 2 variants circulating in Greece. J Vet Diagn Invest 22: 737-740.

Parrish CR, Have P, Foreyt WJ, Evermann JF, Senda M, Carmichael LE (1988) The global spread and replacement of canine parvovirus strains. J Gen Virol 69: 1111-1116.

Parrish CR, O'Connell PH, Evermann JF, Carmichael LE (1985) Natural variation of canine parvovirus. Science 230: 1046-1048.

Parrish CR (1991) Mapping specific functions in the capsid structure of canine parvovirus and feline panleukopenia virus using infectious plasmid clones. Virology 183: 195-205.

Parrish CR, Aquadro CF, Carmichael LE (1988) Canine host range and a specific epitope map along with variant sequences in the capsid protein gene of canine parvovirus and related feline, mink, and raccoon parvoviruses. Virology 166: 293-307.

Perez R, Francia L, Romero V, Maya L, Lopez I, Hernandez $M(\mathbf{2 0 0 7})$ First detection of canine parvovirus type $2 \mathrm{c}$ in South America. Vet Microbiol 124: 147-152.

Phromnoi S, Sirinarumitr K, Sirinarumitr T (2010) Sequence analysis of VP2 gene of canine parvovirus isolates in Thailand. Virus Genes 41: 23-29.

Pinto LD, Streck AF, Goncalves KR, Souza CK, Corbellini AO, Corbellini LG, Canal CW (2012) Typing of canine parvovirus strains circulating in Brazil between 2008 and 2010. Virus Res 165: 29-33.

Puentes R, Eliopulos N, Pérez R, Franco G, Sosa K, Bianchi $\mathrm{P}$, Furtado A, Hübner SO, Esteves PA (2012) Isolation and characterization of canine parvovirus type $2 \mathrm{c}$ (CPV-2c) from symptomatic puppies. Braz J Microbiol 43: 1005-1009. 
Saitou N, Nei M (1987) The Neighbor-joining method: A new method for reconstructing phylogenetic trees. Mol Biol Evol 4: 406-425.

Shackelton LA, Parrish CR, Truyen U, Holmes EC (2005) High rate of viral evolution associated with the emergence of carnivore parvovirus. Proc Natl Acad Sci USA 102: 379-384

Siegl G, Bates RC, Berns KI, Carter BJ, Kelly DC, Kurstak E, Tattersall $\mathrm{P}(\mathbf{1 9 8 5})$ Characteristics and taxonomy of Parvoviridae. Intervirology 23: 61-73.

Spibey N, Greenwood NM, Sutton D, Chalmers WS, Tarpey I (2008) Canine parvovirus type 2 vaccine protects against virulent challenge with type $2 \mathrm{c}$ virus. Vet Microbiol 128: 48-55.

Stankevicius A, Salomskas A (1998) Epizootic pecularities of parvovirus infection in Lithuanian dog population. Vet zootech-lith 5: 89-94.

Sutton D, Vinberg C, Gustafsson A, Pearce J, Greenwood $\mathrm{N}$ (2013) Canine parvovirus type 2c identified from an outbreak of severe gastroenteritis in a litter in Sweden. Acta Vet Scand 55: 64.

Tamura K, Nei M (1993) Estimation of the number of nucleotide substitutions in the control region of mitochondrial DNA in humans and chimpanzees. Mol Biol Evol 10: 512-526.
Tamura K, Stecher G, Peterson D, Filipski A, Kumar $S$ (2013) MEGA6: Molecular evolutionary genetics analysis version 6.0. Mol Biol Evol 30: 2725-2729.

Thompson JD, Gibson TJ, Plewniak F, Jeanmougin F, Higgins DG (1997). The CLUSTAL_X windows interface: flexible strategies for multiple sequence alignment aided by quality analysis tools. Nucleic Acids Res 25: 4876-4882.

Truyen U (1999) Emergence and recent evolution of canine parvovirus. Vet Microbiol 69: 47-50.

Truyen U (2006) Evolution of canine parvovirus-a need for new vaccines? Vet Microbiol 117: 9-13.

Truyen U, Gruenberg A, Chang SF, Obermaier B, Veijalainen P, Parrish CR (1995) Evolution of the feline-subgroup of parvoviruses and the control of canine host range in vivo. J Virol 69: 4702-4710.

Wang HC, Chen WD, Lin SL, Chan JP, Wong ML (2005) Phylogenetic analysis of canine parvovirus VP2 gene in Taiwan. Virus Genes 31: 171-174.

Yoon SH, Jeong W, Kim HJ, An DJ (2009) Molecular insights into the phylogeny of canine parvo virus 2(CPV-2) with emphasis on Korean isolates: a Bayesian approach. Arch Virol 154: 1353-1360. 